\title{
BMJ Open Associations between major chain fast- food outlet availability and change in body mass index: a longitudinal observational study of women from Victoria, Australia
}

Karen E Lamb, ${ }^{1}$ Lukar E Thornton, ${ }^{1}$ Dana Lee Olstad, ${ }^{1}$ Ester Cerin, ${ }^{2,3}$ Kylie Ball ${ }^{1}$

To cite: Lamb KE, Thornton LE, Olstad DL, et al. Associations between major chain fastfood outlet availability and change in body mass index: a longitudinal observational study of women from Victoria, Australia. BMJ Open 2017;7:e016594. doi:10.1136/ bmjopen-2017-016594

- Prepublication history and additional material for this paper are available online. To view please visit the journal (http:// dx.doi.org/10.1136/bmjopen2017-016594).

Received 26 February 2017 Revised 24 August 2017 Accepted 31 August 2017

CrossMark

${ }^{1}$ School of Exercise and Nutrition Sciences, Deakin University, Institute for Physical Activity and Nutrition (IPAN), Geelong, Victoria, Australia

${ }^{2}$ Australian Catholic University, Institute for Health and Ageing, Melbourne, Victoria, Australia ${ }^{3}$ School of Public Health, The University of Hong Kong, Hong Kong, China

Correspondence to

Dr Karen E Lamb;

karen.lamb@deakin.edu.au

\section{ABSTRACT}

Objectives The residential neighbourhood fast-food environment has the potential to lead to increased levels of obesity by providing opportunities for residents to consume energy-dense products. This longitudinal study aimed to examine whether change in body mass index (BMI) differed dependent on major chain fast-food outlet availability among women residing in disadvantaged neighbourhoods.

Setting Eighty disadvantaged neighbourhoods in Victoria, Australia.

Participants Sample of 882 women aged 18-46 years at baseline (wave I: 2007/2008) who remained at the same residential location at all three waves (wave II: 2010/2011; wave III: 2012/2013) of the Resilience for Eating and Activity Despite Inequality study.

Primary outcome BMI based on self-reported height and weight at each wave.

Results There was no evidence of an interaction between time and the number of major chain fast-food outlets within $2(p=0.88), 3(p=0.66)$ or $5 \mathrm{~km}(p=0.24)$ in the multilevel models of BMI. Furthermore, there was no evidence of an interaction between time and change in availability at any distance and BMI.

Conclusions Change in BMI was not found to differ by residential major chain fast-food outlet availability among Victorian women residing in disadvantaged neighbourhoods. It may be that exposure to fast-food outlets around other locations regularly visited influence change in BMI. Future research needs to consider what environments are the key sources for accessing and consuming fast food and how these relate to $\mathrm{BMI}$ and obesity risk.

\section{INTRODUCTION}

Obesity is a major public health concern, with WHO reporting that an estimated $35 \%$ of adults are classed as overweight and $11 \%$ as obese worldwide. ${ }^{1}$ In Australia, approximately $60 \%$ of adults are now overweight or obese, ${ }^{2}$ with higher prevalence among those in socioeconomically disadvantaged and rural communities. ${ }^{3}$ As excess of weight
Strengths and limitations of this study

- This study is one of very few longitudinal studies of its kind and enables examination of how major chain fast-food outlet availability is associated with change in body mass index (BMI).

- The collection of major chain fast-food outlet data at a follow-up wave enabled examination of associations between change in exposure and change in BMI.

- Loss to follow-up may have limited generalisability of findings beyond the sample. However, descriptive characteristics for major chain fast food availability and $\mathrm{BMI}$ at baseline were comparable for those who did and did not participate in all waves of Resilience for Eating and Activity Despite Inequality.

- BMI was based on self-reported height and weight rather than objective measurements.

is associated with a number of comorbidities, the high prevalence of overweight and obesity in Australian adults poses problems for the long-term health of the nation and places an enormous economic burden on the health system. ${ }^{45}$

While individual factors, both behavioural and genetic, ${ }^{6}$ have known links to overweight and obesity, there is a growing recognition that the built environment also plays a role. ${ }^{78}$ As outlined in ecological models of health behaviour, ${ }^{9} 10$ the residential neighbourhood food environment has the potential to influence individual dietary behaviours by, for example, offering the opportunity to purchase affordable healthy products in local supermarkets or by providing options for residents to buy inexpensive energy-dense products at fast-food outlets. The proliferation of fast-food outlets has potentially normalised the consumption of energy-dense products which may influence body mass index (BMI). 
This may lead to higher levels of obesity, particularly among those residing in disadvantaged neighbourhoods given research showing higher fast-food outlet availability in these neighbourhoods. ${ }^{11}$

In the USA, researchers have proposed zoning laws that restrict the location of fast-food outlets, comparable to those created for alcohol outlets, to help curb the obesity epidemic. These include setting minimum distances for fast-food outlets from youth-orientated facilities or limiting the number of fast-food outlets in an area. ${ }^{1213}$ Similarly, recent consultations with senior representatives in government departments in Australia have highlighted planning measures involving the restriction of fast-food outlets as a potential avenue for promoting healthier eating environments. ${ }^{14}$ However, managing fast-food proliferation in Australia is complicated due to Australian planning laws. ${ }^{15}$ In addition, it is unclear how successful regulations such as these would be in practice given mixed findings from studies examining associations between the residential fast-food environment and BMI or obesity. ${ }^{16}{ }^{17}$ While studies in the $\mathrm{UK}^{18}{ }^{18}$ Canada $^{19}$ and the USA ${ }^{20-23}$ have found evidence that availability of fast-food outlets is positively associated with BMI, others in Australia ${ }^{24}$ and the $\mathrm{USA}^{25}$ have shown no evidence of an association, while some in Australia ${ }^{26}$ and New Zealand ${ }^{27}$ have found evidence of negative associations.

Although there are several methodological differences across these studies including the definitions of fast food and neighbourhoods, one clear drawback to most studies is their reliance on cross-sectional data. This limits the ability to detect temporal associations or to examine within-individual change in BMI or obesity. ${ }^{28}$ This is important as those with higher fast-food outlet availability at baseline may have greater increases in BMI over time than those with lower availability. Furthermore, longitudinal observational studies of the food environment have the benefit of allowing examination of how changes in the environment can influence changes in health outcomes. Those that have a higher increase in fast-food outlets over time may have a larger increase in BMI due to the increased opportunity to purchase and consume energy-dense foods.

The aim of this study was to examine longitudinal associations between the fast-food environment and BMI among women residing in disadvantaged neighbourhoods in Victoria, Australia. As it is commonly hypothesised that fast-food outlet availability is associated with higher BMI, we extended this hypothesis in this longitudinal analysis to assess whether (i) women with higher residential availability of major chain fast-food outlets at baseline would have a greater increase in BMI than those with lower availability and (ii) women who lived in neighbourhoods with a larger increase in availability of major chain fast-food outlets would have a greater increase in BMI than women who lived in neighbourhoods with little or no change in availability.

\section{METHODS}

Study participants were from the Resilience for Eating and Activity Despite Inequality (READI) cohort. Full details of the sampling procedures are provided elsewhere. ${ }^{29}$ In brief, in 2007, women aged between 18 and 46 years were sampled using the Australian electoral roll (it is compulsory for Australian citizens to register on the electoral roll). Sampling took place within 40 urban and 40 rural randomly selected socioeconomically disadvantaged suburbs. Suburbs were considered disadvantaged if they were in the bottom third of the Australian Bureau of Statistics Index of Relative Socio-economic Disadvantage. In total, 4349 women (39\% response rate) were recruited at wave I $(2007 / 2008)$ and completed a postal survey. Among women eligible to remain in the study (ie, who remained resident of a READI suburb) and who consented to further follow-up ( $\mathrm{n}=3019), 1912$ completed the survey at wave II $(2010 / 2011)$ and 1560 at wave III (2012/2013).

Women were eligible for inclusion in this analysis if they participated in all three waves of READI $(n=1560)$, reported that they were not pregnant at all three waves $(n=1341)$ and had reported weight at more than one time point, meaning that within individual change in BMI could be assessed $(n=1302)$. Participants whose address could not be geocoded at wave I $(n=5)$ were omitted as exposure variables could not be derived for these participants. Due to data errors (inconsistent date of birth and very large change of $>80 \mathrm{~kg}$ in weight between waves), two further participants were excluded. This resulted in a sample of 1295 participants. Finally, to avoid possible confounding due to changing residential location, only women who remained at the same address during the study duration were examined. Thus, a final sample of 882 participants was considered in this study. Descriptive statistics for the full sample at wave I, those who completed all waves of data and those who only completed wave I are provided in online supplementary table S1.

\section{Body mass index}

The weight $(\mathrm{kg})$ and height $(\mathrm{m})$ of participants were self-reported at each wave which enabled BMI $\left(\mathrm{kg} / \mathrm{m}^{2}\right)$ to be calculated. Research has shown close correspondence between self-reported and objectively measured body weight among Australian women, with no evidence of a difference found between self-report and objectively measured BMI (mean difference $=0.12 \mathrm{~kg} / \mathrm{m}^{2}, 95 \% \mathrm{CI}$ -0.13 to $0.37 \mathrm{~kg} / \mathrm{m}^{2}$ ) in the Australian Longitudinal Study of Women's Health. ${ }^{30}$

\section{Major chain fast-food availability}

At baseline (2007), the locations of 10 major chain fastfood outlets in Australia were sourced from company websites. The chains considered (Domino's Pizza, Eagle Boys Pizza, Kentucky Fried Chicken (KFC), Hungry Jack's, Nando's, Pizza Haven, Pizza Hut, McDonald's, Red Rooster and Subway) were chosen as each of these chains had $>100$ outlets across Australia according to the 
Table 1 Descriptive characteristics for Resilience for Eating and Activity Despite Inequality participants ( $n=882$ )

Variable

Wave I

Wave II

Wave III

Outcome variable

Body mass index $\left(\mathrm{kg} / \mathrm{m}^{2}\right)$

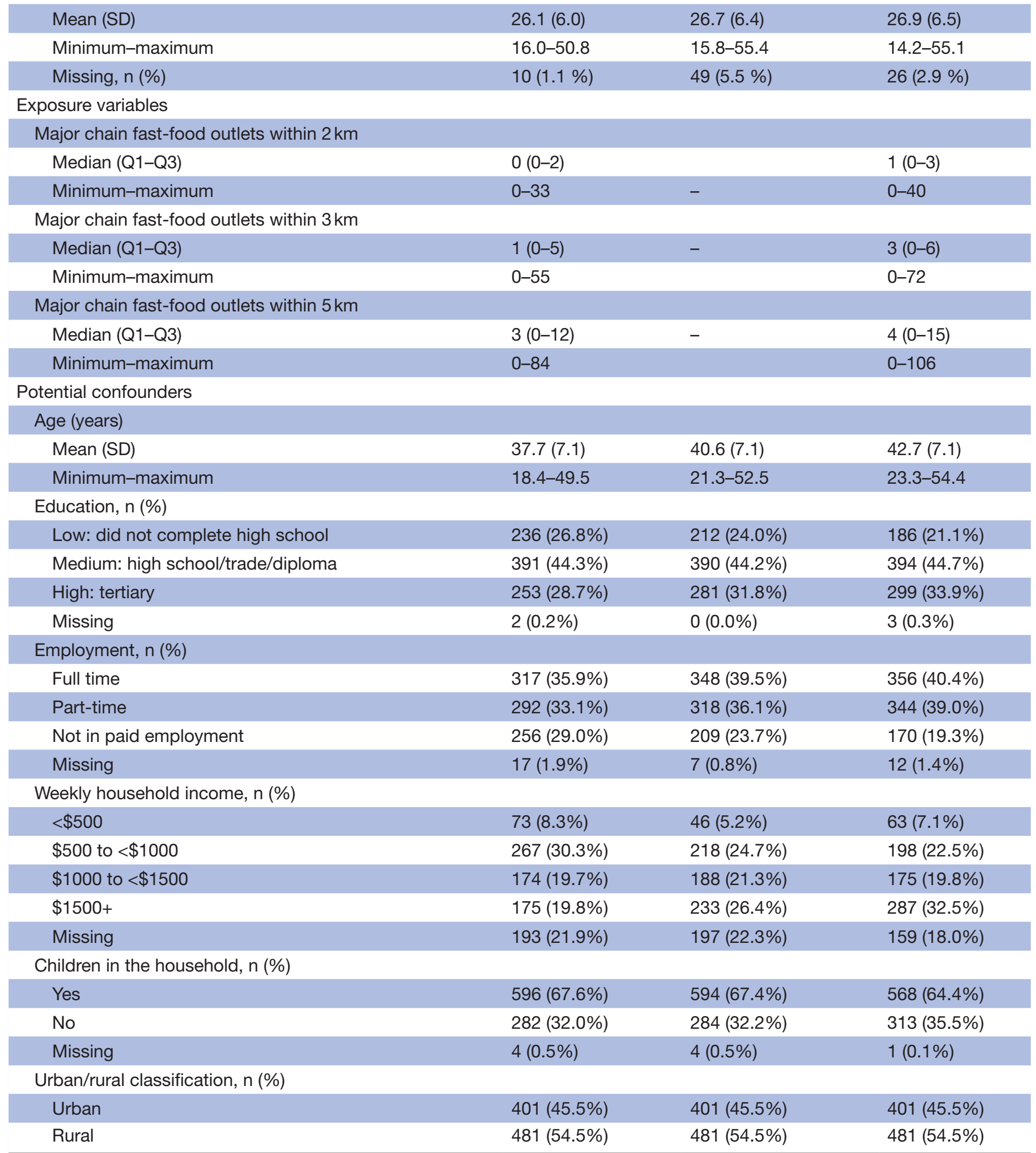

Q1, quartile 1; Q3, quartile 3. 
Table 2 Multilevel linear regression models of the associations between availability of major chain fast-food outlets at baseline and body mass index from wave I to wave III $(n=882)$

\begin{tabular}{|c|c|c|c|}
\hline & Model 1 & Model 2 & Model 3 \\
\hline Variable & $\begin{array}{l}\text { Major chain fast-food outlets } \\
\text { within } 2 \mathrm{~km} \\
\text { Coefficient }(95 \% \mathrm{Cl})\end{array}$ & $\begin{array}{l}\text { Major chain fast-food outlets } \\
\text { within } 3 \mathrm{~km} \\
\text { Coefficient }(95 \% \mathrm{Cl})\end{array}$ & $\begin{array}{l}\text { Major chain fast-food outlets } \\
\text { within } 5 \mathrm{~km} \\
\text { Coefficient }(95 \% \mathrm{Cl})\end{array}$ \\
\hline Intercept & $26.68(25.71 \text { to } 27.65)^{\star \star *}$ & $26.88(25.89 \text { to } 27.88)^{\star \star \star}$ & $27.27(26.32 \text { to } 28.21)^{\star \star \star}$ \\
\hline Time (years) & $0.17(0.13 \text { to } 0.22)^{\star \star \star}$ & $0.17(0.12 \text { to } 0.21)^{\star \star \star}$ & $0.16(0.11 \text { to } 0.21)^{\star \star \star}$ \\
\hline \multicolumn{4}{|c|}{ Fast-food availability exposure } \\
\hline Number of outlets & $-0.06(-0.21$ to 0.10$)$ & $-0.06(-0.13$ to 0.02$)$ & $-0.05(-0.07 \text { to }-0.03)^{\star \star \star}$ \\
\hline $\begin{array}{l}\text { Number of outlets and } \\
\text { time interaction }\end{array}$ & $-0.001(-0.011$ to 0.010$)$ & 0.001 (-0.004 to 0.006$)$ & $0.001(-0.001$ to 0.003$)$ \\
\hline \multicolumn{4}{|l|}{ Potential confounders $\dagger$} \\
\hline Age at baselineł & $0.08(0.03 \text { to } 0.14)^{\star \star}$ & $0.08(0.03 \text { to } 0.14)^{\star \star}$ & $0.08(0.03 \text { to } 0.14)^{\star \star}$ \\
\hline \multicolumn{4}{|l|}{ Education } \\
\hline Medium & $-0.36(-0.98$ to 0.27$)$ & $-0.35(-0.97$ to 0.28$)$ & $-0.32(-0.95$ to 0.31$)$ \\
\hline High & $-0.96(-1.76 \text { to }-0.15)^{\star}$ & $-0.94(-1.74 \text { to }-0.14)^{\star}$ & $-0.88(-1.69 \text { to }-0.07)^{\star}$ \\
\hline \multicolumn{4}{|l|}{ Employment } \\
\hline Part-time & $-0.22(-0.51$ to 0.08$)$ & $-0.22(-0.51$ to 0.08$)$ & $-0.22(-0.51$ to 0.08$)$ \\
\hline Not in employment & $-0.06(-0.42$ to 0.30$)$ & $-0.06(-0.42$ to 0.30$)$ & $-0.06(-0.42$ to 0.31$)$ \\
\hline \multicolumn{4}{|l|}{ Household income } \\
\hline$\$ 500$ to $<\$ 1000$ & $-0.12(-0.61$ to 0.37$)$ & $-0.12(-0.62$ to 0.37$)$ & $-0.13(-0.62$ to 0.37$)$ \\
\hline$\$ 1000$ to $<\$ 1500$ & $-0.04(-0.53$ to 0.44$)$ & $-0.04(-0.52$ to 0.44$)$ & $-0.04(-0.52$ to 0.44$)$ \\
\hline$\$ 1500+$ & $-0.04(-0.57$ to 0.49$)$ & $-0.03(-0.56$ to 0.50$)$ & $-0.02(-0.55$ to 0.51$)$ \\
\hline \multicolumn{4}{|l|}{ Children in household } \\
\hline No & $-0.23(-0.66$ to 0.21$)$ & $-0.21(-0.65$ to 0.22$)$ & $-0.20(-0.64$ to 0.24$)$ \\
\hline \multicolumn{4}{|l|}{ Urban } \\
\hline \multirow[t]{2}{*}{ Rural } & $0.34(-0.52$ to 1.20$)$ & $0.15(-0.75$ to 1.04$)$ & $-0.26(-1.13$ to 0.62$)$ \\
\hline & Variance & Variance & Variance \\
\hline Intercept & 34.58 (29.81 to 40.11$)$ & 34.52 (29.74 to 40.06$)$ & 34.34 (29.57 to 39.89$)$ \\
\hline Slope & 0.12 (0.08 to 0.17 ) & $0.12(0.08$ to 0.17$)$ & 0.12 (0.08 to 0.17 ) \\
\hline \multirow[t]{2}{*}{ Residual } & 2.17 (1.74 to 2.71$)$ & 2.17 (1.74 to 2.71$)$ & 2.17 (1.74 to 2.71$)$ \\
\hline & Covariance & Covariance & Covariance \\
\hline Intercept, slope ${ }^{\S}$ & $0.19(-0.13$ to 0.67$)$ & $0.19(-0.13$ to 0.68$)$ & $0.19(-0.12$ to 0.68$)$ \\
\hline
\end{tabular}

†Reference categories: low education, full-time employment, $<\$ 500$, yes children in household, urban.

$\ddagger$ Age was centred at 37 years.

$\S$ Considers covariance between these random components.

${ }^{*} \mathrm{p}<0.05 ;{ }^{* *} \mathrm{p}<0.01 ;{ }^{* * *} \mathrm{p}<0.001$.

Franchise Council of Australia. ${ }^{31}$ The locations of the fast-food outlets in Victoria were geocoded using ArcMap V.9.1, with any unmatched address points geocoded by hand after searching for the nearest address match. Outlet addresses were checked for errors and duplicate records based on trading name, suburb and proximity to another outlet of the same type.

Follow-up fast-food location data were collected in 2014 to approximately correspond with the timing of READI wave III data collection. A commercial data source was purchased from Sensis which included the names and locations of the same chains examined in wave I. Eagle Boys Pizza acquired Pizza Haven mid-2008, meaning only nine chains were considered at follow-up, with Pizza Haven outlets captured as Eagle Boys Pizza at the follow-up time point. These data were validated against company websites, with a high level of agreement between the two sources which reflects the fact that company websites are likely to be a key source of data for companies like Sensis. Geocoding of these data was undertaken in ArcGIS V.10.2.

Participants' home addresses were geocoded and the road network distance between each address and each of the chain fast-food outlets (to a maximum distance of $5 \mathrm{~km}$ ) was calculated for each time point separately. This enabled the number of fast-food outlets within 
Table 3 Multilevel linear regression associations of the change in availability of major chain fast-food outlets and body mass index from wave I to wave III $(n=882)$

\begin{tabular}{|c|c|c|c|}
\hline & Model 1 & Model 2 & Model 3 \\
\hline Variable & $\begin{array}{l}\text { Major chain fast-food } \\
\text { outlets within } 2 \mathrm{~km} \\
\text { Coefficient }(95 \% \mathrm{Cl})\end{array}$ & $\begin{array}{l}\text { Major chain fast-food } \\
\text { outlets within } 3 \mathrm{~km} \\
\text { Coefficient }(95 \% \mathrm{Cl})\end{array}$ & $\begin{array}{l}\text { Major chain fast-food outlets } \\
\text { within } 5 \mathrm{~km} \\
\text { Coefficient }(95 \% \mathrm{Cl})\end{array}$ \\
\hline Intercept & $26.84(25.92 \text { to } 27.77)^{\star \star \star}$ & $27.19(26.21 \text { to } 28.18)^{\star \star \star}$ & $27.48(26.54,28.43)^{\star \star \star}$ \\
\hline Time (years) & $0.10(0.03 \text { to } 0.16)^{\star \star}$ & $0.09(0.01 \text { to } 0.16)^{*}$ & $0.08(0.01 \text { to } 0.16)^{\star}$ \\
\hline \multicolumn{4}{|l|}{ Fast-food availability exposure } \\
\hline Number of outlets & $-0.07(-0.23$ to 0.08$)$ & $-0.04(-0.12$ to 0.05$)$ & $-0.02(-0.07$ to 0.02$)$ \\
\hline Change in outlets & $0.01(-0.44$ to 0.46$)$ & $-0.17(-0.41$ to 0.06$)$ & $-0.11(-0.27$ to 0.04$)$ \\
\hline $\begin{array}{l}\text { Change in outlets and time } \\
\text { interaction }\end{array}$ & $-0.001(-0.023$ to 0.021$)$ & $0.008(-0.013$ to 0.029$)$ & $0.006(-0.003$ to 0.015$)$ \\
\hline \multicolumn{4}{|l|}{ Potential confounders $\dagger$} \\
\hline Age at baseline ${ }^{\ddagger}$ & $0.08(0.02 \text { to } 0.13)^{\star \star}$ & $0.08(0.02 \text { to } 0.14)^{\star \star}$ & $0.08(0.02 \text { to } 0.13)^{\star \star}$ \\
\hline \multicolumn{4}{|l|}{ Education } \\
\hline Medium & $-0.38(-0.99$ to 0.24$)$ & $-0.35(-0.97$ to 0.26$)$ & $-0.35(-0.96$ to 0.27$)$ \\
\hline High & $-1.12(-1.88 \text { to }-0.36)^{\star *}$ & $-1.09(-1.85 \text { to }-0.33)^{\star \star}$ & $-1.06(-1.83 \text { to }-0.30)^{\star \star}$ \\
\hline \multicolumn{4}{|l|}{ Employment } \\
\hline Part-time & $-0.24(-0.54$ to 0.06$)$ & $-0.24(-0.54$ to 0.06$)$ & $-0.24(-0.54$ to 0.06$)$ \\
\hline Not in employment & $-0.09(-0.44$ to 0.27$)$ & $-0.08(-0.44$ to 0.28$)$ & $-0.09(-0.44$ to 0.27$)$ \\
\hline \multicolumn{4}{|l|}{ Household income } \\
\hline$\$ 500$ to $<\$ 1000$ & $-0.11(-0.60$ to 0.39$)$ & $-0.11(-0.61$ to 0.38$)$ & $-0.11(-0.61$ to 0.38$)$ \\
\hline$\$ 1000$ to $<\$ 1500$ & $-0.02(-0.51$ to 0.48$)$ & $0.01(-0.50$ to 0.48$)$ & $-0.01(-0.50$ to 0.48$)$ \\
\hline$\$ 1500+$ & $-0.01(-0.55$ to 0.52$)$ & 0.002 (-0.53 to 0.54$)$ & $0.01(-0.53$ to 0.55$)$ \\
\hline \multicolumn{4}{|l|}{ Children in household } \\
\hline No & $-0.20(-0.62$ to 0.22$)$ & $-0.19(-0.62$ to 0.23$)$ & $-0.18(-0.60$ to 0.24$)$ \\
\hline \multicolumn{4}{|l|}{ Urban } \\
\hline \multirow[t]{2}{*}{ Rural } & $0.31(-0.49$ to 1.12$)$ & $-0.01(-0.92$ to 0.90$)$ & $-0.32(-1.20$ to 0.55$)$ \\
\hline & Variance & Variance & Variance \\
\hline Intercept & 33.91 (29.15 to 39.43$)$ & 33.80 (29.10 to 39.27$)$ & 33.62 (28.89 to 39.12$)$ \\
\hline Slope & 0.05 (0.02 to 0.10$)$ & 0.05 (0.02 to 0.10$)$ & 0.05 (0.02 to 0.10$)$ \\
\hline \multirow[t]{2}{*}{ Residual } & 2.58 (2.08 to 3.20$)$ & 2.57 (2.07 to 3.19 ) & 2.57 (2.08 to 3.19 ) \\
\hline & Covariance & Covariance & Covariance \\
\hline Intercept, slope ${ }^{\S}$ & $0.24(-0.06$ to 0.87$)$ & $0.24(-0.06$ to 0.86$)$ & $0.24(-0.06$ to 0.87$)$ \\
\hline
\end{tabular}

†Reference categories: low education, full-time employment, $<\$ 500$, yes children in household, urban.

${ }^{\ddagger}$ Age was centred at 37 years.

${ }^{\S}$ Considers covariance between these random components.

${ }^{*} \mathrm{p}<0.05 ;{ }^{* *} \mathrm{p}<0.01 ;{ }^{* \star *} \mathrm{p}<0.001$.

2,3 and $5 \mathrm{~km}$ distances, based on distances used elsewhere, ${ }^{18} 26^{32-34}$ to be determined at waves I and III. Although fast-food purchases may be thought to occur at more proximal walking distances to home, a recent study of food purchasing behaviours of Melbourne residents showed that the median distance from home of food purchases was $4.6 \mathrm{~km}$ for purchases of hot takeaway items. ${ }^{35}$ Therefore, we chose to consider buffer distances of up to $5 \mathrm{~km}$. Three distances were chosen to enable the sensitivity of the findings to the choice of buffer distance to be examined. The availability of fast-food outlets was thus defined as the number of fast-food outlets within 2, 3 or $5 \mathrm{~km}$ road network buffers from participants' homes.

\section{Potential confounders}

Possible confounders were identified from previous literature. These included the individual-level variables of participant age, children in the household (no/yes), highest educational attainment (low: did not complete high school; medium: completed high school, trade certificate or diploma; high: completed tertiary education), employment 
status (not employed; employed part-time; employed full time) and weekly household income $(<\$ 500 ; \$ 500$ to $<\$ 700 ; \$ 700$ to $<\$ 1000 ; \$ 1000$ to $<\$ 1500 ; \geq \$ 1500)$ and the suburb-level variable of urban or rural location. Country of birth was also hypothesised to be a potential confounder. However, as the overall number of non-Australian births was small $(\mathrm{n}=81)$ and spread across multiple nations, we did not adjust for country of birth in the analysis but did conduct a sensitivity analysis where only those born in Australia were examined.

\section{Statistical analysis}

Under the assumption that the missing covariate data were Missing At Random, we used multiple imputation with chained equations (50 imputations) to impute missing confounder data across all waves using the userwritten ice program in Stata V.12.0. ${ }^{36} 37$ The amount of missing data for each variable is reported in table 1. Data were imputed in wide format and the imputation model included the outcome variables, exposure variables and all potential confounders described previously, in addition to auxiliary variables (country of birth, and marital status and personal income at waves I, II and III). In sensitivity analyses, a complete case analysis was conducted under the assumption that missing confounder data were Missing Completely At Random.

Multilevel linear regression models were fitted including time (years since baseline) as a predictor of BMI to assess change in BMI over the three waves. As the aim of this study was to examine whether the change in BMI differed dependent on the number of fast-food outlets at baseline, an interaction between each of the fast-food outlet availability measures and time was included in separate multilevel models. This means that the main effects of both time and fast-food outlets should not be interpreted without consideration of their combined effect. The multilevel models included both a random intercept and a random slope for time to allow each participant to have a unique intercept and rate of change. All models adjusted for potential confounders, allowing these to vary over time, and accounted for clustering of participants within suburbs.

To address the second hypothesis, the change in the availability of major chain fast-food outlets within each buffer distance during the study was calculated by subtracting the number of fast-food outlets at wave I from the number at wave III. Change in availability of fast-food outlets was used as an exposure in multilevel models, adjusting for baseline fast-food availability to account for the magnitude of initial availability. An interaction between change in fast-food outlet availability and time was examined to determine if the change in BMI over time differed depending on the change in availability of fast-food outlets.

\section{RESULTS}

Average BMI increased from $26.1 \mathrm{~kg} / \mathrm{m}^{2}(\mathrm{SD}=6.0)$ at baseline to $26.9 \mathrm{~kg} / \mathrm{m}^{2}(\mathrm{SD}=6.5)$ at wave III (table 1$)$. In this sample, the median number of major chain fast-food outlets available at baseline was $0(\mathrm{IQR}=2)$ within $2 \mathrm{~km}$ of participants' homes, $1 \quad(\mathrm{IQR}=5)$ within $3 \mathrm{~km}$ and 3 $(\mathrm{IQR}=12)$ within $5 \mathrm{~km}$, increasing to $1(\mathrm{IQR}=3)$ within $2 \mathrm{~km}, 3(\mathrm{IQR}=6)$ within $3 \mathrm{~km}$ and $4(\mathrm{IQR}=15)$ within $5 \mathrm{~km}$ at wave III.

\section{Availability of major chain fast-food outlets at baseline and change in BMI}

On average, BMI was found to increase by approximately $0.17 \mathrm{~kg} / \mathrm{m}^{2}$ each year (table 2). This corresponds to an increase in weight of $0.4 \mathrm{~kg}$ (or $0.9 \mathrm{lbs}$ ) each year for an Australian woman of average height $(161.8 \mathrm{~cm})$. We found no evidence of an interaction between time and the baseline number of major chain fast-food outlets within 2 $(\mathrm{p}=0.88), 3(\mathrm{p}=0.66)$ or $5 \mathrm{~km}(\mathrm{p}=0.24)$. Therefore, there was no evidence to suggest that the change in BMI over time was influenced by the local residential availability of major chain fast-food outlets at baseline.

\section{Change in availability of major chain fast-food outlets and change in BMI}

Many participants did not experience a change in the number of major chain fast-food outlets in proximity to their homes between waves I and III: 609 (68\%) had the same number within $2 \mathrm{~km}$ at both time points, $469(53 \%)$ had the same number within $3 \mathrm{~km}$ and $374(42 \%)$ had the same number within $5 \mathrm{~km}$ at both time points. Very few participants had a decrease in the number of major chain fast-food outlets within these distances $(2 \mathrm{~km}$ : 26 (2.9\%) participants; $3 \mathrm{~km}: 18(2.0 \%)$ participants; $5 \mathrm{~km}$ : 17 (1.9\%) participants). The median change in major chain fast-food outlets was $0(\mathrm{IQR}=1$; range from -5 to 10$)$ within $2 \mathrm{~km}, 0$ ( $\mathrm{IQR}=2$; range from -5 to 17 ) within $3 \mathrm{~km}$ and $1(\mathrm{IQR}=3$; range from -6 to 45$)$ within $5 \mathrm{~km}$.

The results from multilevel models of associations between change in major chain fast-food availability between Waves I and III and BMI are presented in table 3. We found no evidence that the rate of change in BMI differed dependent on the change in the number of major chain fast-food outlets within $2 \mathrm{~km}(\mathrm{p}=0.95)$, the number of major chain fast-food outlets within $3 \mathrm{~km}$ $(\mathrm{p}=0.46)$ or the number of major chain fast-food outlets within $5 \mathrm{~km}(\mathrm{p}=0.18)$.

\section{Sensitivity analyses}

Three sensitivity analyses were conducted. The first excluded those born overseas, the second included those who changed address between waves I and III (but remained within a READI suburb) and the third involved a complete case analysis for those who remained at the same address across all three waves. The results from these analyses were consistent with those presented in tables 2 and 3. There was no evidence that the change in BMI differed by either baseline major chain fast-food outlet availability or change in major chain fast-food outlet availability.

\section{DISCUSSION}

We hypothesised that increased major chain fast-food outlet availability within the residential environment 
would be associated with greater increases in BMI over time. However, the results from this longitudinal study of women living in disadvantaged neighbourhoods in Victoria, Australia, found no evidence to support this hypothesis. Furthermore, there was no evidence that the rate of change in BMI differed dependent on the change in the number of major chain fast-food outlets over the study period.

Given that the average change in BMI in this sample over the 5-year study was small (increase of $0.8 \mathrm{~kg}$ / $\mathrm{m}^{2}$ ) and that studies of adults in the USA and Canada which established associations between fast-food outlets and BMI only identified small effect sizes, ${ }^{192}{ }^{20}$ it is perhaps unsurprising that we did not find evidence of an association. Furthermore, our ability to determine the influence of change in fast-food outlet availability on change in BMI may have been limited by the fact that there was little change in the number of major chain fast-food outlets between waves I and III. Our findings suggesting no evidence of an association between fast-food outlet availability and change in BMI are consistent with cross-sectional findings indicating no evidence of an association between fastfood outlet availability and BMI in a previous analysis of the READI sample. ${ }^{38}$ These findings are also consistent with null findings observed in both cross-sectional $^{2539}$ and longitudinal studies ${ }^{40}$ of adults from the USA which were not restricted to those residing in disadvantaged neighbourhoods. The present findings contrast that of another longitudinal study from the USA which found evidence that greater distance to fast-food outlets was associated with lower BMI among women. ${ }^{41}$ However, the effect sizes in this study were small, with only a $0.19 \mathrm{~kg} / \mathrm{m}^{2}$ decrease in BMI with each additional $1 \mathrm{~km}$ to the nearest fast-food outlet.

While the fast-food environment around home was not associated with change in BMI in this sample, it may be that exposure to fast-food outlets in other locations people regularly visit is associated with BMI. Although it has been shown that the number of fastfood outlets around the workplace was not associated with BMI among women in cross-sectional research, ${ }^{42}$ recent research exploring individual activity spaces has shown some evidence of a positive association between fast-food outlet availability and overweight status. ${ }^{43}$ Furthermore, considering the co-location of fast-food outlets with other types of food outlets, or other built environment characteristics, may be important to gain a better understanding of the range of options available to individuals. ${ }^{40}{ }^{44}$ For example, cross-sectional studies have shown positive associations between availability of fast-food outlets and BMI or obesity when considered relative to other food outlet types. ${ }^{45}{ }^{46}$ Furthermore, in Victoria, research has found that those who reside in areas with unhealthy food outlets also have high access to healthy food outlets, thus residents have choices other than fast food. ${ }^{47}$ Therefore, it could be that the participants in our study had a range of both healthy and unhealthy food outlets available to them. This may explain the null associations found since the presence of alternative food outlet options may counteract any influence of the availability of fast-food outlets on BMI. More detailed food environment data would be required on a variety of food outlet types to study this. In addition, it is important to clearly categorise the food outlet types. Without on-the-ground assessment of food outlets, which is often not feasible in studies across a whole state such as this, it can be challenging to clearly identify the types of food provided in independent food outlets to correctly categorise these. Furthermore, defining meaningful relative measures of unhealthy to healthy food outlets can be challenging as, for example, a ratio of one of the number of unhealthy to healthy food outlets does not differentiate between those who have one outlet of each type to those who have 10 of each. ${ }^{48}$ Therefore, a ratio measure does not distinguish between individuals with high versus low access to fastfood outlets.

While this study adds to the existing literature by examining prospective associations between the availability of fast-food outlets and change in BMI, it does have some limitations. This study relied on self-reported measures of height and weight. However, self-reported BMI has been shown to correspond closely to objectively measured BMI in Australian women. ${ }^{30}$ Furthermore, although this study considered objective measures of the fast-food environment, we were not able to ground truth these outlets across the state of Victoria, although we validated these data against other sources. In addition, this study only considered major chain fast-food outlets. Findings may have differed had we included independent takeaway outlets in our analyses. It may be that other independent takeaway outlets could influence BMI. Finally, there was substantial loss to follow-up in this study with only $36 \%$ of recruited participants completing all survey waves. Descriptive characteristics for fast food availability and BMI at baseline were comparable for those who did and did not participate in all waves of READI (supplementary table S1). However, among those who did not complete follow-up, a lower proportion of participants had tertiary education (23.4\% compared with $29.9 \%$ ), a higher proportion were not in paid employment $(32.9 \%$ compared with $29.2 \%$ ) and a lower proportion reported income in the highest category ( $15.1 \%$ compared with $21.1 \%$ ). Thus, the results reported may not be representative of those of lower socioeconomic status residing within disadvantaged neighbourhoods.

\section{Summary}

Although this study identified null findings regarding associations between the availability of major chain fast-food outlets and change in BMI, the results are important as they provide an advance on mostly cross-sectional findings in this area and provide insight into associations among women residing in disadvantaged neighbourhoods. 
Given that null findings regarding associations between fast-food outlet availability and BMI or overweight and obesity have been identified in the literature, ${ }^{16}$ obesity prevention advocacy efforts focused on changes to the built environment that are based on restricting fast-food outlets may not be sufficient. Policies to improve the residential food environment should adopt a more holistic approach rather than focusing on a single outlet type. Future research needs to consider what environments are the key sources for accessing and consuming fast food and how these relate to BMI and obesity risk.

Acknowledgements The authors acknowledge the contributions of Ralf-Dieter Schroers for geocoding and validating the fast food outlet data, the project manager Michelle Jackson, the field staff and the study participants.

Contributors KEL and LT conceived of the study and led the development of the analysis plan. LT was instrumental in deriving the GIS exposure measures. KB conceived and led the READI study, data included in this manuscript. EC provided support on analytical concerns. DL0 provided support in drafting the introduction and discussion. All authors contributed to the analysis plan and drafting the manuscript.

Funding The READI study was funded by an Australian National Health and Medical Research Council Strategic Award (\#374241).

Disclaimer The contents of this paper are the responsibility of the authors and do not reflect the views of the NHMRC.

Competing interests KEL was supported by a Deakin University Alfred Deakin Postdoctoral Research Fellowship (RM 27751). DL0 was supported by a Research Fellowship from the Canadian Institutes of Health Research. EC was supported by an ARC Future Fellowship (FT3; \#140100085). KB was supported by a National Health and Medical Research Council (NHMRC) Principal Research Fellowship (ID 1042442).

Ethics approval Deakin University Human Research Ethics Committee.

Provenance and peer review Not commissioned; externally peer reviewed.

Data sharing statement Data are available on request from the lead investigator on the study, Professor Kylie Ball (kylie.ball@deakin.edu.au).

Open Access This is an Open Access article distributed in accordance with the Creative Commons Attribution Non Commercial (CC BY-NC 4.0) license, which permits others to distribute, remix, adapt, build upon this work non-commercially, and license their derivative works on different terms, provided the original work is properly cited and the use is non-commercial. See: http://creativecommons.org/ licenses/by-nc/4.0/

(c) Article author(s) (or their employer(s) unless otherwise stated in the text of the article) 2017. All rights reserved. No commercial use is permitted unless otherwise expressly granted.

\section{REFERENCES}

1. World Health Organization. Obesity and overweight. http://www.who. int/mediacentre/factsheets/fs311/en/ (accessed 19 Jul 2017).

2. Australian Government Australian Institute of Health and Welfare. Overweight and obesity. http://www.aihw.gov.au/overweight-andobesity/ (accessed 19 Jul 2017).

3. Australian Bureau of Statistics. Overweight and obesity in adults. 2004-05 http://www.abs.gov.au/ausstats/abs@.nsf/Latestproducts/ 4719.0Main\%20Features32004-05?opendocument\&tabname= Summary\&prodno $=4719.0 \&$ issue $=2004-05 \&$ num $=\& v i e w=($ accessed 19 Jul 2017)

4. Withrow D, Alter DA. The economic burden of obesity worldwide: a systematic review of the direct costs of obesity. Obes Rev 2011:12:131-41.

5. Colagiuri S, Lee CM, Colagiuri R, et al. The cost of overweight and obesity in Australia. Med J Aust 2010;192:260-4.

6. Marti A, Moreno-Aliaga MJ, Hebebrand J, et al. Genes, lifestyles and obesity. Int J Obes 2004;28(Suppl 3):S29-S36.

7. Wakefield J. Fighting obesity through the built environment. Environ Health Perspect 2004;112:a616-a618.
8. Cohen DA. Obesity and the built environment: changes in environmental cues cause energy imbalances. Int $J$ Obes 2008;32(Suppl 7):S137-S142.

9. Glanz K, Sallis JF, Saelens BE, et al. Healthy nutrition environments: concepts and measures. Am J Health Promot 2005;19:330-3.

10. Brug J. Determinants of healthy eating: motivation, abilities and environmental opportunities. Fam Pract 2008;25(Suppl 1):i50-i55

11. Thornton LE, Lamb KE, Ball K. Fast food restaurant locations according to socioeconomic disadvantage, urban-regional locality, and schools within Victoria, Australia. SSM Popul Health 2016;2:1-9.

12. Ashe $M$, Jernigan $D$, Kline $R$, et al. Land use planning and the control of alcohol, tobacco, firearms, and fast food restaurants. Am J Public Health 2003;93:1404-8.

13. Chen SE, Florax RJ. Zoning for health: the obesity epidemic and opportunities for local policy intervention. J Nutr 2010;140:1181S-4.

14. Shill J, Mavoa H, Allender S, et al. Government regulation to promote healthy food environments--a view from inside state governments. Obes Rev 2012;13:162-73.

15. Taylor EJ. Fast food planning conflicts in Victoria 1969-2012: is every unhappy family restaurant unhappy in its own way? Australian Planner 2015;52:114-26.

16. Cobb LK, Appel LJ, Franco M, et al. The relationship of the local food environment with obesity: a systematic review of methods, study quality, and results. Obesity 2015;23:1331-44.

17. Fleischhacker SE, Evenson KR, Rodriguez DA, et al. A systematic review of fast food access studies. Obes Rev 2011;12:e460-e471.

18. Burgoine T, Forouhi NG, Griffin SJ, et al. Does neighborhood fastfood outlet exposure amplify inequalities in diet and obesity? a cross-sectional study. Am J Clin Nutr 2016;103:1540-7.

19. Hollands S, Campbell MK, Gilliland J, et al. Association between neighbourhood fast-food and full-service restaurant density and body mass index: a cross-sectional study of Canadian adults. Can $J$ Public Health 2014;105:172-8.

20. Dubowitz T, Ghosh-Dastidar M, Eibner C, et al. The Women's Health Initiative: The food environment, neighborhood socioeconomic status, BMI, and blood pressure. Obesity 2012;20:862-71.

21. Kruger DJ, Greenberg E, Murphy JB, et al. Local concentration of fast-food outlets is associated with poor nutrition and obesity. Am J Health Promot 2014;28:340-3.

22. Li F, Harmer PA, Cardinal BJ, et al. Built environment, adiposity, and physical activity in adults aged 50-75. Am J Prev Med 2008;35:38-46.

23. Mehta NK, Chang VW. Weight status and restaurant availability a multilevel analysis. Am J Prev Med 2008;34:127-33.

24. Simmons D, McKenzie A, Eaton S, et al. Choice and availability of takeaway and restaurant food is not related to the prevalence of adult obesity in rural communities in Australia. Int $J$ Obes 2005;29:703-10.

25. Lopez RP. Neighborhood risk factors for obesity. Obesity 2007;15:2111-9.

26. Crawford DA, Timperio AF, Salmon JA, et al. Neighbourhood fast food outlets and obesity in children and adults: the CLAN Study. Int J Pediatr Obes 2008;3:249-56.

27. Pearce J, Hiscock R, Blakely T, et al. A national study of the association between neighbourhood access to fast-food outlets and the diet and weight of local residents. Health Place 2009;15:193-7.

28. Mackenbach JD, Rutter $\mathrm{H}$, Compernolle $\mathrm{S}$, et al. Obesogenic environments: a systematic review of the association between the physical environment and adult weight status, the SPOTLIGHT project. BMC Public Health 2014;14:233.

29. Ball K, Cleland V, Salmon J, et al. Cohort profile: the resilience for eating and activity despite inequality (READI) study. Int J Epidemiol 2013;42:1629-39.

30. Burton NW, Brown W, Dobson A. Accuracy of body mass index estimated from self-reported height and weight in mid-aged Australian women. Aust N Z J Public Health 2010;34:620-3.

31. Franchise Council of Australia. Franchise Business. http://www. franchisebusiness.com.au/ (accessed 19 Jul 2017).

32. Richardson AS, Meyer KA, Howard AG, et al. Multiple pathways from the neighborhood food environment to increased body mass index through dietary behaviors: a structural equation-based analysis in the CARDIA study. Health Place 2015;36:74-87.

33. Meyer KA, Boone-Heinonen J, Duffey KJ, et al. Combined measure of neighborhood food and physical activity environments and weightrelated outcomes: The CARDIA study. Health Place 2015;33:9-18.

34. Hattori A, An R, Sturm R. Neighborhood food outlets, diet, and obesity among California adults, 2007 and 2009. Prev Chronic Dis 2013;10:E35.

35. Thornton LE, Crawford DA, Lamb KE, et al. Where do people purchase food? a novel approach to investigating food purchasing locations. Int J Health Geogr 2017;16:9. 
36. Royston P. Multiple imputation of missing values: update of ice. The Stata Journal 2005;5:527-36.

37. Carlin JB, Galati JC, Royston P. A new framework for managing and analyzing multiply imputed data in stata. The Stata Journal 2008;8:49-67.

38. Tseng M, Thornton LE, Lamb KE, et al. Is neighbourhood obesogenicity associated with body mass index in women? application of an obesogenicity index in socioeconomically disadvantaged neighbourhoods. Health Place 2014;30:20-7.

39. Wang MC, Kim S, Gonzalez AA, et al. Socioeconomic and foodrelated physical characteristics of the neighbourhood environment are associated with body mass index. J Epidemiol Community Health 2007:61:491-8.

40. Boone-Heinonen J, Diez-Roux AV, Goff DC, et al. The neighborhood energy balance equation: does neighborhood food retail environment + physical activity environment = obesity? The CARDIA study. PLoS One 2013;8:e85141.

41. Block JP, Christakis NA, O'Malley AJ, et al. Proximity to food establishments and body mass index in the framingham heart study offspring cohort over 30 years. Am J Epidemiol 2011:174:1108-14.

42. Jeffery RW, Baxter J, McGuire M, et al. Are fast food restaurants an environmental risk factor for obesity? Int J Behav Nutr Phys Act 2006;3:2.
43. Lebel A, Kestens $\mathrm{Y}$, Pampalon R, et al. Local context influence, activity space, and foodscape exposure in two Canadian metropolitan settings: is daily mobility exposure associated with overweight? J Obes 2012;2012:1-9.

44. Myers CA, Denstel KD, Broyles ST. The context of context: Examining the associations between healthy and unhealthy measures of neighborhood food, physical activity, and social environments. Prev Med 2016;93:21-6.

45. Stark JH, Neckerman K, Lovasi GS, et al. Neighbourhood food environments and body mass index among New York City adults. $J$ Epidemiol Community Health 2013;67:736-42.

46. Polsky JY, Moineddin R, Dunn JR, et al. Absolute and relative densities of fast-food versus other restaurants in relation to weight status: does restaurant mix matter? Prev Med 2016;82:28-34.

47. Thornton LE, Kavanagh AM. Association between fast food purchasing and the local food environment. Nutr Diabetes 2012;2:e53.

48. Lamb KE, Thornton LE, Cerin E, et al. Statistical approaches used to assess the equity of access to food outlets: a systematic review. AIMS Public Health 2015;2:358-401. 